Research Article

\title{
Stability Analysis and Derived Control Measures for Rock Surrounding a Roadway in a Lower Coal Seam under Concentrated Stress of a Coal Pillar
}

\author{
Zhuoyue Sun $\mathbb{D}^{1,2,3}$ Yongzheng $W u\left(\mathbb{D},{ }^{1,2,3}\right.$ Zhiguo Lu $\mathbb{D}^{1,2,3}$ Youliang Feng, ${ }^{1,2,3}$ \\ Xiaowei Chu, ${ }^{1,2,3}$ and Kang Yi ${ }^{1,2,4}$ \\ ${ }^{1}$ Coal Mining Branch, China Coal Research Institute, Beijing 100013, China \\ ${ }^{2}$ Coal Mining and Designing Department, Tiandi Science and Technology Co., Ltd., Beijing 100013, China \\ ${ }^{3}$ State Key Laboratory of Coal Mining and Clean Utilization (China Coal Research Institute), Beijing 100013, China \\ ${ }^{4}$ School of Energy \& Mining Engineering, China University of Mining and Technology (Beijing), Beijing 100083, China
}

Correspondence should be addressed to Yongzheng Wu; tiandiwyz@163.com and Zhiguo Lu; cumtblzg@163.com

Received 22 October 2020; Revised 6 November 2020; Accepted 13 November 2020; Published 3 December 2020

Academic Editor: Guangchao Zhang

Copyright $\odot 2020$ Zhuoyue Sun et al. This is an open access article distributed under the Creative Commons Attribution License, which permits unrestricted use, distribution, and reproduction in any medium, provided the original work is properly cited.

Numerical simulations have often been used in close-distance coal seam studies. However, numerical simulations can contain certain subjective and objective limitations, such as high randomness and excessively simplified models. In this study, closedistance coal seams were mechanically modeled based on the half-plane theory. An analytical solution of the floor stress distribution was derived and visualized using Mathematica software. The principal stress difference was regarded as a stability criterion for the rock surrounding the roadway. Then, the evolution laws of the floor principal stress difference under different factors that influence stability were further examined. Finally, stability control measures for the rock surrounding the roadway in the lower coal seam were proposed. The results indicated the following: (1) The principal stress difference of the floor considers the centerline of the upper coal pillar as a symmetry axis and transmits radially downward. The principal stress difference in the rock surrounding the roadway gradually decreases as the distance from the upper coal pillar increases and can be ranked in the following order: left rib > roof > right rib. (2) The minimum principal stress difference zones are located at the center of the left and right "spirals," which are obliquely below the edge of the upper coal pillar. This is an ideal position for the lower coal seam roadway. (3) The shallowness of the roadway, a small stress concentration coefficient, high level of coal cohesion, large coal internal friction angle, and appropriate lengthening of the working face of the upper coal seam are conducive to the stability of the lower coal seam roadway. (4) Through bolt (cable) support, borehole pressure relief, and pregrouting measures, the roof-to-floor and rib-to-rib convergence of the 13313 return airway is significantly reduced, and the stability of the rock surrounding the roadway is substantially improved. This research provides a theoretical basis and field experience for stabilizing the lower coal seam roadways in close-distance coal seams.

\section{Introduction}

Coal is an important fuel resource in China $[1,2]$. For historical reasons and because of technological limitations in mining, numerous coalmines prioritize the mining of a single thick coal seam $[3,4]$. With the depletion of coal resources under suitable conditions, several coalmines have begun to mine close-distance coal seams $[5,6]$. Because of the short distance between adjacent coal seams, the upper coal seam affects the roof integrity of the lower coal seam after mining, and the remaining coal pillars of the upper coal seam can lead to stress concentration in the floor, thereby significantly impacting the stress environment of the lower coal seam $[7,8]$. A lower coal seam is typically more complicated and difficult to mine than a single coal seam [9]. Therefore, it is necessary to study the concentrated stress of the upper coal pillar, which is of great significance for 
analyzing roadway deformations and formulating control measures for close-distance coal seams.

The supporting pressure of a coal pillar is affected by the pressure of overlying strata within a certain range and is related to its width and properties [10]. Accordingly, the floor stress distributed by a coal pillar is highly complicated. To clarify the distribution of floor stress, some scholars [11-15] have established numerical models of close-distance coal seams based on FLAC3D or UDEC and studied the changes and characteristics of floor stress after mining the upper coal seam. Other scholars [16-19] have established mechanical models to qualitatively analyze the floor stress distribution, followed by numerical simulations to simulate the floor stress distribution to obtain quantitative data. Several scholars have been unable to circumvent numerical simulations when studying close-distance coal seams. However, the results obtained by the numerical simulations are relatively random, and the inevitable objective and subjective factors will cause errors, varying the simulation results from the field observations.

One of the major research topics related to mining closedistance coal seams is determining the reasonable placement of the lower coal seam roadway. Currently, lower coal seam roadway layouts are primarily characterized as either internal misaligned, external misaligned, or overlapping layouts. Because the internal misaligned layout is used to build roadways in stress reduction areas, several scholars [20-23] regard this layout as their first choice. However, even though the lower coal seam roadway is located in the stress reduction area, the surrounding rock deformation is still severe in field measurements. Studies [24-28] have shown that the stress of coal and rock mass units in various directions are rather different, causing uneven stress in the rock surrounding the roadway. Consequently, it is essential to consider the stress uniformity of the surrounding rock when determining the location of the lower coal seam roadway.

The objective of this study is to develop a better understanding of roadway stability in close-distance coal seams so that more effective stability control measures can be generated to improve the lower coal seam roadway performance. To reveal the influence of concentrated stress caused by coal pillars on the stability of the lower coal seam roadway, this study establishes a mechanical model of closedistance coal seams based on the half-plane theory and derives an analytical solution to the floor stress distribution problem. The principal stress difference is selected as the stability criterion of the rock surrounding the roadway, and the distribution of the principal stress difference is visualized using Mathematica software by Wolfram Research. Thereafter, the influence of roadway depth, stress concentration coefficient, coal cohesion, coal internal friction angle, and the working face length of the upper coal seam on roadway stability is examined. Finally, this paper presents three stability control measures based on the above analysis and verifies the theoretical analysis results through field measurements.

The concentrated stress of the upper coal pillar significantly affects close-distance coal seams. Based on the Sunjiagou coalmine, Shanxi Province, China, this study focuses on the concentrated stress caused by coal pillars through theoretical analysis and field tests. This research is based on theoretical analysis and directly visualizes the calculation results with mathematical software, thus avoiding the parameter adjustments of numerical simulation. The principal stress difference that can reflect the stress uniformity is used as the criterion to make the basis of the roadway layout more reasonable. In addition, this study provides control measures and field verification for the rocks surrounding the roadway under similar conditions.

\section{Engineering Background}

The Sunjiagou coalmine primarily exploits the No. 11 and No. 13 coal seams, with average thicknesses of $2.19 \mathrm{~m}$ and $13 \mathrm{~m}$, respectively. The two coal seams have simple structures, with inclination angles of $1^{\circ}-6^{\circ}$, which are nearly horizontal and stable. The average depth of the No. 11 coal seam is $223 \mathrm{~m}$, and the two coal seams are $14 \mathrm{~m}$ apart. It is a typical close-distance coal seam. Figure 1 shows the interrelationship between the comprehensive geological histogram of the Sunjiagou coalmine and the position of the roadway.

At present, the 13309 working face is being mined. The 11103 and 11105 working faces have been mined to stop lines, leaving a $15 \mathrm{~m}$ wide coal pillar between them. To ensure the connection between mining and excavation, the 13311 return airway was excavated beforehand, and there is a $25 \mathrm{~m}$ wide coal pillar between the 13311 return airway and the 13309 haulage way. The 13309 haulage way is located below the 11103 goaf, which has a misaligned internal layout; the 13311 return airway is located directly below the 11103 haulage way, and they form an overlapping layout. During the excavation of the 13311 return airway, roof cracking, spalling, and caving phenomena occurred, while the roof-to-floor and rib-to-rib convergence was more than $2 \mathrm{~m}$, which threatened the safety of the coalmine.

\section{Analysis of the Floor Stress Caused by the Upper Coal Pillar}

3.1. Construction of the Close-Distance Coal Seam Mechanical Model. To explore stress in the rock surrounding the 13311 return airway, a mechanical model of close-distance coal seams was established. After the completion of mining at the 11103 and 11105 working faces, a support system for "coal walls-collapsed gangues" was formed. The surrounding rock stress is redistributed under the influence of mining. Then, the stress concentration is generated on the remaining coal pillar and transfers downward, causing stress redistribution in the floor. Within a certain range from the inner coal pillar to its edge, the bearing capacity and supporting pressure are in a state of limit equilibrium. According to the rock mass limit equilibrium theory [29], the distance from the peak of the supporting pressure to the edge of the coal pillar, that is, the width of the plastic zone $x_{0}$, is calculated as

$$
x_{0}=\frac{m}{2 \zeta f} \ln \frac{k \gamma H+C \cot \phi}{\zeta\left(p_{1}+C \cot \phi\right)} .
$$




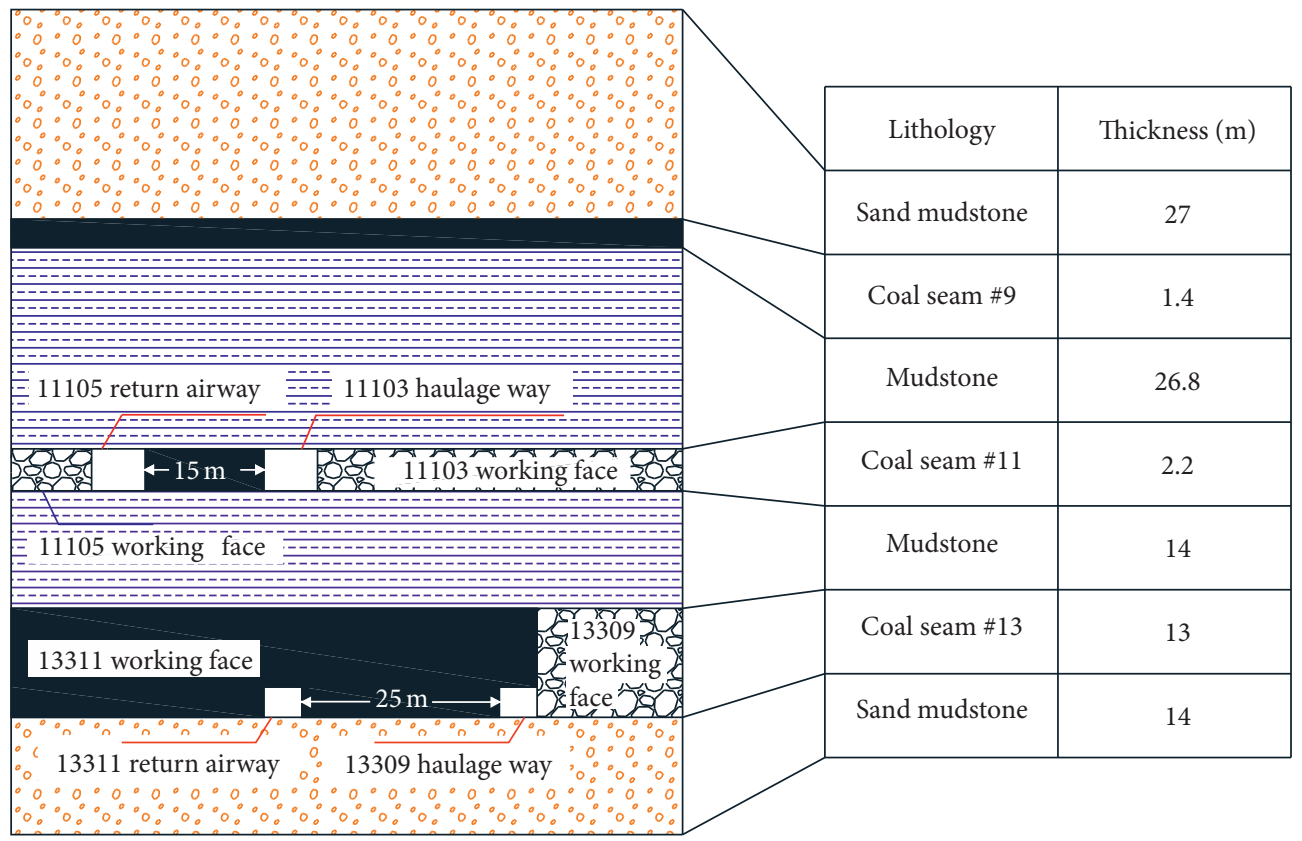

(a)

(b)

FIgURE 1: Comprehensive geological histogram and spatial position of the roadway.

In the formula, $m$ is the mining height of the coal seam, $m ; \zeta$ is the triaxial stress coefficient, $\zeta=(1+\sin \varphi) /(1-\sin \varphi) ; f$ is the friction factor between the coal seam and the roof (floor), $f=\tan \varphi / 4 ; k$ is the stress concentration coefficient; $\gamma$ is the average volume force of the overlying strata, $\mathrm{kN} / \mathrm{m}^{3} ; H$ is the depth of the working face, $m$; $C$ is the coal cohesion, $\mathrm{MPa}, \varphi$ is the coal internal friction angle, ${ }^{\circ}$; and $p_{1}$ is the hydraulic support resistance at the rib, $\mathrm{MPa}$.

The value of each parameter is determined according to the geological data of the Sunjiagou coalmine: $m=2.19 \mathrm{~m}$; $\gamma=25 \mathrm{kN} / \mathrm{m}^{3} ; \quad H=223 \mathrm{~m} ; \quad C=1.5 \mathrm{MPa}, \varphi=26^{\circ} ; \zeta=2.561 ;$ $f=0.122$. The hydraulic support resistance at the rib has no evident influence on the range of the limit equilibrium zone [29]; therefore, $p_{1}=0$. According to the field data of the Sunjiagou coalmine [30], the stress concentration coefficient $k=3$.

Through calculation, the width of the plastic zone $x_{0}=3.2 \mathrm{~m}$. Research shows that the range of the supporting pressure is twice the distance from the edge of the coal pillar to the peak [31]; that is, the width of the elastic zone $x_{1}=3.2 \mathrm{~m}$. Because the width of the coal pillar between the 11103 and 11105 working faces is $15 \mathrm{~m}$, the width of the original rock stress zone is $2.2 \mathrm{~m}$. Therefore, the supporting pressure at the coal pillar is saddle-shaped and nonuniform.

Excluding the influence of tectonic stress, according to the half-plane theory, the stress distribution caused by mining is simplified as a model of the normal distribution stress of the half-plane [32]. Considering the intersection of the centerline of the coal pillar and the floor as the origin, a rectangular coordinate system is established with the positive direction of the $x$-axis being vertical to the floor downward and the positive direction of the $y$-axis being parallel to the working face to the left. Figure 2 demonstrates the floor stress of the upper coal seam after mining.

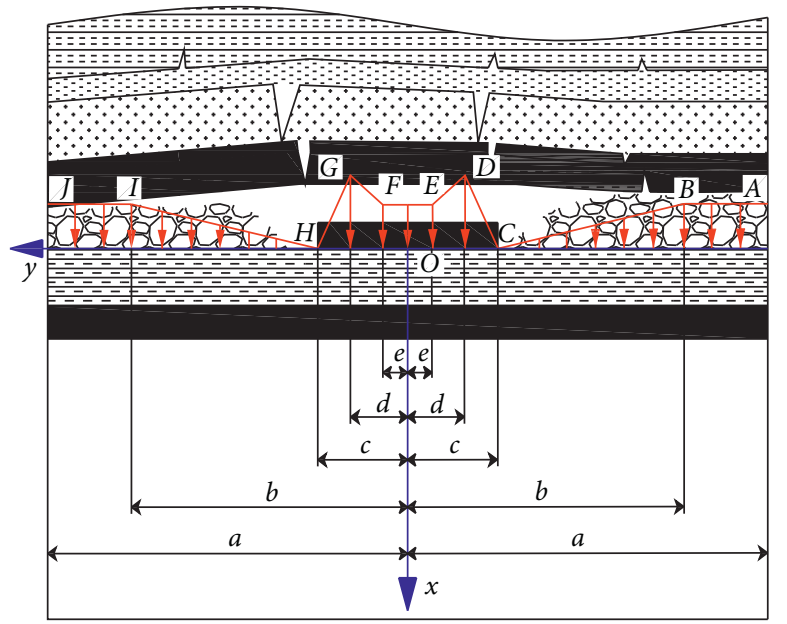

FIgURE 2: The mechanical model of close-distance coal seams.

As shown in Figure 2, the $\mathrm{CD}$ and GH segments are plastic zones; the DE and FG segments are elastic zones; the $D$ and $G$ points are the peak of the supporting pressure with a value of $k \gamma H$; and the EF segment, being the original rock stress zone, has a value of $\gamma H$. The $a-e$ distances range between the endpoint of each load and the origin. After the working face is mined, the direct roof collapses into the goaf; the basic roof bends, sinks, then rotates, breaks, and finally touches the gangue and compacts. The $\mathrm{BC}$ and $\mathrm{HI}$ segments are gradually compacted zones, and the $\mathrm{AB}$ and IJ segments are the original rock stress zones. In the coordinate system presented in Figure 2, the functional expressions of the load $q_{\mathrm{i}}$ of the A-J segments are as follows: 


$$
\begin{array}{ll}
q_{1}=\gamma H, & (-a \leq \xi \leq-b), \\
q_{2}=\frac{\gamma H}{c-b}(\xi+c), & (-b \leq \xi \leq-c), \\
q_{3}=\frac{k \gamma H}{c-d}(\xi+c), & (-c \leq \xi \leq-d), \\
q_{4}=\frac{\gamma H}{e-d}[(k-1) \xi+(k e-d)], & (-d \leq \xi \leq-e), \\
q_{5}=\gamma H, & (-e \leq \xi \leq e), \\
q_{6}=\frac{\gamma H}{e-d}[(1-k) \xi+(k e-d)], & (e \leq \xi \leq d), \\
q_{7}=\frac{k \gamma H}{c-d}(-\xi+c), & (d \leq \xi \leq c), \\
q_{9}=\frac{\gamma H}{c-b}(-\xi+c), & (b \leq \xi \leq a) . \\
& (c \leq \xi \leq b), \\
& \\
&
\end{array}
$$

Substituting the aforementioned functional expressions of $q_{\mathrm{i}}$ into equation (3) for integral operation, the stress component caused by each $q_{\mathrm{i}}$ at any point in the floor can be obtained:

$$
\left.\begin{array}{c}
\sigma_{x}=-\frac{2}{\pi} \int_{-b}^{a} \frac{q x^{3} d \xi}{\left[x^{2}+(y-\xi)^{2}\right]^{2}}, \\
\sigma_{y}=-\frac{2}{\pi} \int_{-b}^{a} \frac{q x(y-\xi)^{2} d \xi}{\left[x^{2}+(y-\xi)^{2}\right]^{2}}, \\
\tau_{x y}=-\frac{2}{\pi} \int_{-b}^{a} \frac{q x^{2}(y-\xi) d \xi}{\left[x^{2}+(y-\xi)^{2}\right]^{2}} .
\end{array}\right\}
$$

(2)

Figure 2 shows that the floor stress distribution model is asymmetrically distributed; therefore, the formula can be derived only by selecting the load on the right side of the origin. Through calculation, the stress component caused by the $\mathrm{AB}, \mathrm{BC}, \mathrm{CD}, \mathrm{DE}$, and $\mathrm{EO}$ segments is represented by

$$
\begin{aligned}
& \sigma_{x 1}=\frac{\gamma H}{\pi}\left[\arctan \frac{y+a}{x}-\arctan \frac{y+b}{x}+\frac{x(y+a)}{x^{2}+(y+a)^{2}}-\frac{x(y+b)}{x^{2}+(y+b)^{2}},\right] \\
& \left.\sigma_{y 1}=\frac{\gamma H}{\pi}\left[\arctan \frac{y+a}{x}-\arctan \frac{y+b}{x}-\frac{x(y+a)}{x^{2}+(y+a)^{2}}+\frac{x(y+b)}{x^{2}+(y+b)^{2}}\right],\right\} \\
& \tau_{x y 1}=-\frac{\gamma H}{\pi}\left[\frac{x^{2}}{x^{2}+(y+a)^{2}}-\frac{x^{2}}{x^{2}+(y+b)^{2}}\right] . \\
& \sigma_{x 2}=-\frac{\gamma H}{\pi(b-c)}\left[-\frac{x^{3}+x(y+c)^{2}}{x^{2}+(y+c)^{2}}+(y+c)\left(\arctan \frac{y+b}{x}-\arctan \frac{y+c}{x}\right)+\frac{x^{3}+x(y+c)(y+b)}{x^{2}+(y+b)^{2}}\right], \\
& \sigma_{y 2}=-\frac{\gamma H}{\pi(b-c)}\left[\frac{x^{3}+x(y+c)^{2}}{x^{2}+(y+c)^{2}}-\frac{x^{3}+x(y+c)(y+b)}{x^{2}+(y+b)^{2}}-(y+c)\left(\arctan \frac{y+c}{x}-\arctan \frac{y+b}{x}\right)-x \ln \frac{x^{2}+(y+b)^{2}}{x^{2}+(y+c)^{2}}\right], \\
& \tau_{x y 2}=-\frac{\gamma H}{\pi(b-c)}\left[\frac{(b-c) x^{2}}{x^{2}+(y+b)^{2}}-x\left(\arctan \frac{y+b}{x}-\arctan \frac{y+c}{x}\right)\right] .
\end{aligned}
$$




$$
\begin{aligned}
& \sigma_{x 3}=-\frac{k \gamma H}{\pi(c-d)}\left[-\frac{x^{3}+x(y+c)^{2}}{x^{2}+(y+c)^{2}}+(y+c)\left(\arctan \frac{y+d}{x}-\arctan \frac{y+c}{x}\right)+\frac{x^{3}+x(y+c)(y+d)}{x^{2}+(y+d)^{2}}\right], \\
& \left.\sigma_{y 3}=-\frac{k \gamma H}{\pi(c-d)}\left[x \ln \frac{x^{2}+(y+c)^{2}}{x^{2}+(y+d)^{2}}-(y+c)\left(\arctan \frac{y+c}{x}-\arctan \frac{y+d}{x}\right)-\frac{x^{3}+x(y+c)(y+d)}{x^{2}+(y+d)^{2}}+\frac{x(y+c)^{2}+x^{3}}{x^{2}+(y+c)^{2}}\right],\right\} \\
& \tau_{x y 3}=-\frac{k \gamma H}{\pi(c-d)}\left[\frac{(d-c) x^{2}}{x^{2}+(y+d)^{2}}+x\left(\arctan \frac{y+c}{x}-\arctan \frac{y+d}{x}\right)\right] . \\
& \sigma_{x 4}=\frac{\gamma H}{\pi(e-d)}\left[\frac{(k-1) x^{3}+x(y+d) \omega}{x^{2}+(y+d)^{2}}-\frac{(k-1) x^{3}+x(y+e) \omega}{x^{2}+(y+e)^{2}}+\omega\left(\arctan \frac{y+d}{x}-\arctan \frac{y+e}{x}\right)\right] \\
& \sigma_{y 4}=\frac{\gamma H}{\pi(e-d)}\left[\frac{(k-1) x^{3}+x(y+e) \omega}{x^{2}+(y+e)^{2}}-\frac{(k-1) x^{3}+x(y+d) \omega}{x^{2}+(y+d)^{2}}+\omega\left(\arctan \frac{y+d}{x}-\arctan \frac{y+e}{x}\right)\right. \\
& \left.-(k-1) x \ln \frac{x^{2}+(y+d)^{2}}{x^{2}+(y+e)^{2}}\right](\omega=(k-1) y+(k e-d)), \\
& \tau_{x y 4}=\frac{\gamma H}{\pi(e-d)}\left[\frac{(e-d) x^{2}}{x^{2}+(y+e)^{2}}-\frac{(e-d) k x^{2}}{x^{2}+(y+d)^{2}}-(k-1) x\left(\arctan \frac{y+d}{x}-\arctan \frac{y+e}{x}\right)\right] . \\
& \sigma_{x 5}=\frac{\gamma H}{\pi}\left[\arctan \frac{y+e}{x}-\arctan \frac{y}{x}+\frac{x(y+e)}{x^{2}+(y+e)^{2}}-\frac{x y}{x^{2}+y^{2}}\right] \\
& \left.\sigma_{y 5}=\frac{\gamma H}{\pi}\left[\arctan \frac{y+e}{x}-\arctan \frac{y}{x}-\frac{x(y+e)}{x^{2}+(y+e)^{2}}+\frac{x y}{x^{2}+y^{2}}\right],\right\} \\
& \tau_{x y 5}=\frac{\gamma H}{\pi}\left[\frac{x^{2}}{x^{2}+y^{2}}-\frac{x^{2}}{x^{2}+(y+e)^{2}}\right] \text {. }
\end{aligned}
$$

Because of the symmetry of the floor stress distribution, according to equations (4)-(7), the stress components of the OF, FG, GH, HI, and IJ segments can be easily obtained. By superimposing the above stress components, the vertical stress $\sigma_{x}$, the horizontal stress $\sigma_{y}$, and the shear stress $\tau_{x y}$ at any point on the floor under the combined effect of each load can be obtained as follows:

$$
\left.\begin{array}{l}
\sigma_{x}=\sum_{i=1}^{10} \sigma_{x i}, \\
\sigma_{y}=\sum_{i=1}^{10} \sigma_{y i}, \\
\tau_{x y}=\sum_{i=1}^{10} \tau_{x y i} .
\end{array}\right\}
$$

3.2. The Stability Criterion of the Rock Surrounding the Roadway. Studies have shown that arranging the lower coal seam roadway in the stress reduction area will considerably improve the stability of the rock surrounding the roadway when mining close-distance coal seams. However, from field observations, even if the roadway is positioned in an area with a low-stress coefficient, the roadway deformation is still severe, which shows that the stress value is not the only factor affecting the stability of the rock surrounding the roadway [33]. In traditional roadway stability analysis, scholars assess the vertical stress, horizontal stress, and shear stress individually to characterize the surrounding rock stress, but this has certain limitations. Due to the complex conditions of the coal seam, the stress of the coal unit is different in each direction, and the unevenness of the stress has a greater impact on the stability of the rock surrounding the roadway. In this study, the principal stress difference is considered the stability criterion of the rock surrounding the roadway. The principal stress difference combines the effects of vertical stress, horizontal stress, and shear stress, which can appropriately reflect the uniformity of stress. The lower the principal stress difference, the more even the stress distribution and the more stable the rock surrounding the roadway. The principal stress difference $\sigma_{s}$ can be expressed by the following formula:

$$
\sigma_{s}=\left|\sigma_{1}-\sigma_{3}\right| \text {. }
$$

In the formula, $\sigma_{1}$ and $\sigma_{3}$ represent the maximum and minimum principal stresses, respectively. 
3.3. Distribution Law of Principal Stress Difference for 13311 Return Airway. It can be seen from the stability criterion $\sigma_{s}$ that the stability of the rock surrounding the roadway after mining is related to the maximum and minimum principal stresses, which can be obtained by the following formula:

$$
\sigma_{1,3}=\frac{\sigma_{x}+\sigma_{y}}{2} \pm \sqrt{\left(\frac{\sigma_{x}-\sigma_{y}}{2}\right)^{2}+\tau_{x y}^{2}}
$$

Therefore, the principal stress difference $\sigma_{s}$ can be simplified as the following formula:

$$
\sigma_{s}=2 \sqrt{\left(\frac{\sigma_{x}-\sigma_{y}}{2}\right)^{2}+\tau_{x y}^{2}}
$$

In the Sunjiagou coalmine, the width of the plastic zone of the upper coal pillar is $x_{0}=3.2 \mathrm{~m}$, and the width of the elastic zone is $x_{1}=3.2 \mathrm{~m}$. According to the periodic stress data of the 13311 working face [27], the width of the gradually compacted zone is $Z=30 \mathrm{~m}$. As the working face length of the No. 11 coal seam is $L=160 \mathrm{~m}$, the width of the original rock stress zone is $Y=L-2 Z=100 \mathrm{~m}, a=137.5 \mathrm{~m}$, $b=37.5 \mathrm{~m}, c=7.5 \mathrm{~m}, d=4.3 \mathrm{~m}$, and $e=1.1 \mathrm{~m}$. Substituting the values of a-e into equations (2)-(9), the analytical solution to the floor principal stress difference in the upper coal seam is obtained. Then, Mathematica is used to visualize the analytical solution, as illustrated in Figure 3.

As shown in Figure 3, under the influence of the upper coal pillar, the principal stress difference of the floor is transmitted downward radially, with the centerline of the coal pillar as the axis of symmetry. The distribution of the floor principal stress difference shows nonuniformity, and its maximum value appears in the shallow area below the junction of the elastic and plastic zones. The farther away from this zone, the lower the principal stress difference. In addition, there are two "spirals" obliquely below the edges of both sides of the coal pillar, and the center of the "spirals" is the minimum value of the principal stress difference within a certain range, indicating appropriate stability of the rock surrounding the roadway in this area. This is an ideal position for the roadway. The principal stress differences of the midline of the left rib, roof, and right rib of the 13311 return airway are $1.0 \mathrm{MPa}, 0.9 \mathrm{MPa}$, and $0.6 \mathrm{MPa}$, respectively. The principal stress difference between the midline of the left rib and the roof is significantly higher than that of the right rib. This is caused by the different positions of the two ribs and the roof relative to the upper coal pillar. The right rib is far from the upper coal pillar and is less affected by the concentration stress of the coal pillar. The left rib is closer to the upper coal pillar and is considerably affected by the concentration stress of the upper coal pillar; therefore, the principal stress difference in the rock surrounding the roadway is higher on the left and lower on the right. As shown in Figure 4, the deformation of the right rib of the roadway is significantly less than that of the roof and the left rib, which is consistent with the theoretical calculation, indicating that the principal stress difference can be used as the stability criterion for the rock surrounding the roadway.

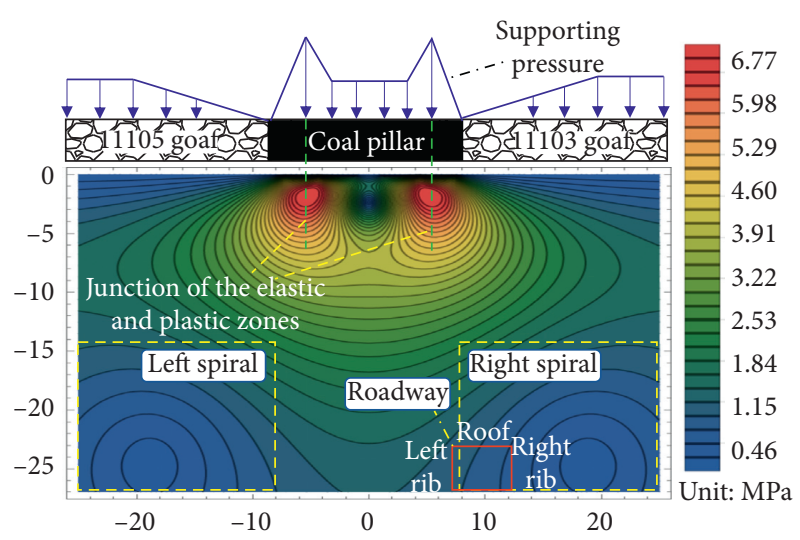

FIgURE 3: Distribution of the floor principal stress difference.

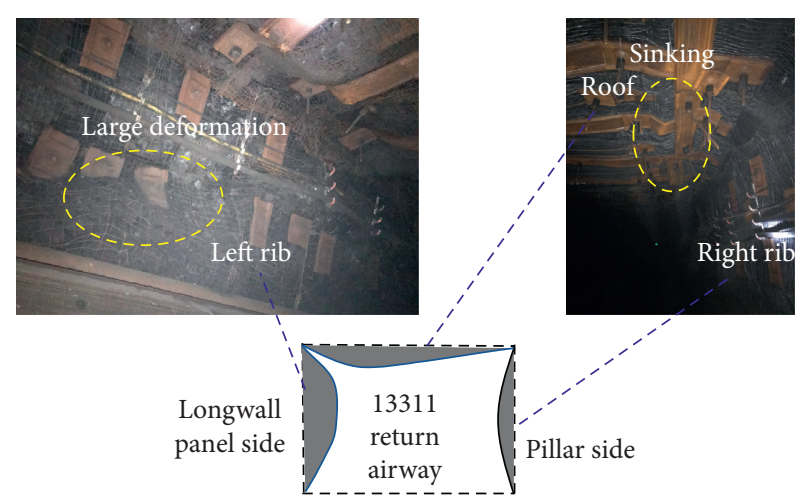

Figure 4: Field deformation of the 13311 return airway.

\section{Analysis of Influencing Factors on the Stability of the Lower Coal Seam Roadway}

From the rock mass limit equilibrium theory and the analytical solution of the floor stress, it can be determined that the stability of the lower coal seam roadway in close-distance coal seams is related to factors such as the roadway depth, stress concentration coefficient, coal cohesion, coal internal friction angle, and length of the upper coal seam working face. The roadway depth is the distance between the roadway and the surface. The self-weight stress of the rock mass is positively correlated with the roadway depth, and the selfweight stress field is the basis for analyzing the redistribution of the stress after mining. The stress concentration coefficient is the ratio of the peak supporting pressure to the nominal stress when not being mined, and its variations can affect the calculation results of the floor stress component. Coal cohesion and the internal friction angle are principal properties of coal. Mining weakens coal and ultimately affects the distribution of the supporting pressure. The length of the upper coal seam working face affects the load on the goaf, thereby affecting the floor stress distribution. To explore the influence of the above factors on the stability of the rock surrounding the roadway, the analysis is conducted based on the evolution law of the roadway stability criterion $\sigma_{s}$. 
4.1. Influence of the Roadway Depth on Roadway Stability. The self-weight stress considerably affects the floor stress distribution, and the roadway depth is an important parameter for calculating the self-weight stress. To study the influence of the roadway depth on the stability of the roadway, $H=160,180,200,220,240$, and $260 \mathrm{~m}$ are selected. Based on Mathematica, the principal stress difference of the midline of the two ribs and the roof of the 13311 return airway is obtained, as shown in Figure 5.

In Figure 5, it can be seen that the principal stress difference of the two ribs and the roof is positively correlated with the roadway depth, indicating that the rock surrounding the deep roadway is less stable than that of the shallow roadway. Under the same roadway depth conditions, the principal stress difference of the surrounding rock can be ranked in the following order: left rib $>$ roof $>$ right rib. This is because the 13311 return airway is in the right "spiral" zone, and the closer to the center of the right "spiral", the smaller the principal stress difference. The left rib is at the left edge of the right "spiral," while the roof and the right rib are relatively close to the center of the right "spiral". Therefore, the sequence of the principal stress difference is as shown in Figure 5. Within the scope of the studied roadway depth, the principal stress difference of the right rib is relatively low. However, the principal stress difference of the left rib, roof, and right rib increases by $240 \%, 210 \%$, and $340 \%$, respectively, when the roadway depth is changed from $160 \mathrm{~m}$ to $260 \mathrm{~m}$. Therefore, as the roadway depth increases, the stability control measures for the right rib must also receive sufficient attention. In summary, the roadway depth has a specific effect on floor stress. The greater the roadway depth, the greater the principal stress difference of the surrounding rock, and the lower the stability of the roadway.

For nearly horizontal coal seams, the change in the roadway depth is not evident, and the principal stress difference does not change significantly. However, for steep seams, it is necessary to gradually strengthen the stability control measures of the deep roadway. Because of the associated engineering challenges, the high principal stress difference of the deep roadway demands close attention to the strength of the bolts (cables).

\subsection{Influence of the Stress Concentration Coefficient on} Roadway Stability. After the excavations for underground engineering, the balance of the original rock stress field is destroyed, the stress will inevitably redistribute, and the stress concentration will appear in the rock surrounding the roadway. According to the tangential stress value, the supporting pressure zone can be divided into stress reduction and stress increase zones. The ratio of the supporting pressure peak to the vertical stress of the original rock stress is the stress concentration coefficient $k$. To study the stress concentration coefficient on the stability of the roadway, $k=2.2,2.4,2.6,2.8,3.0$, and 3.2 are considered. Based on Mathematica, the principal stress difference of the midline of the two ribs and the roof of the 13311 return airway is obtained as demonstrated in Figure 6.

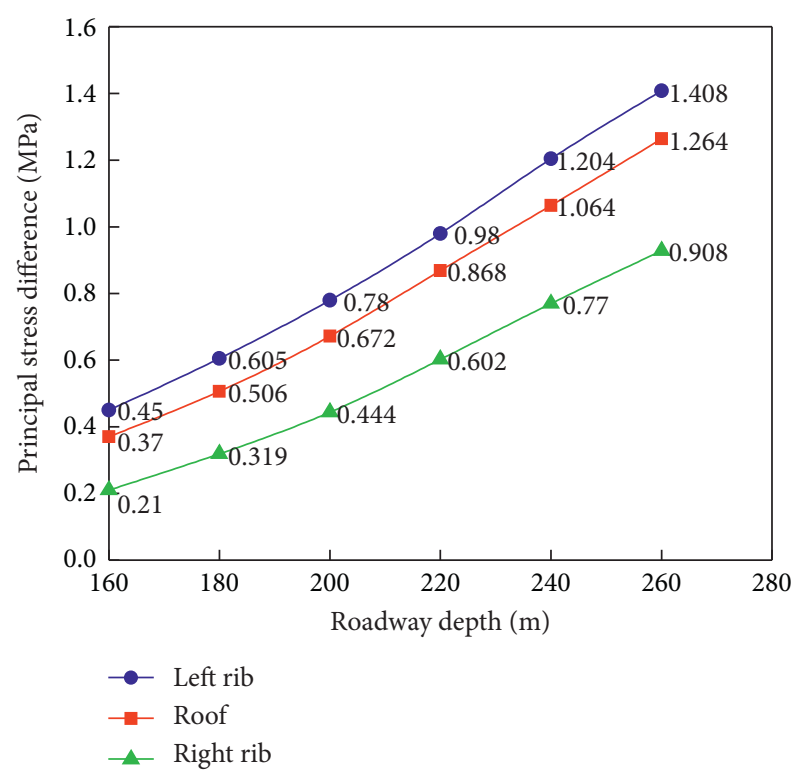

Figure 5: Principal stress difference under different roadway depths.

It can be seen in Figure 6 that the principal stress difference of the left rib and the roof is positively correlated with the stress concentration coefficient, and the right rib first decreases and then increases with the increase in the stress concentration coefficient. This is because the distribution of the principal stress difference migrates with the change in the stress concentration coefficient, affecting the stability of the roadway. According to Figure 6, the midline of the roof and the left rib are both on the left of the right "spiral" within the range of $k=2.2-3.2$, and as the stress concentration coefficient increases, they migrate away from the right "spiral," thereby increasing the principal stress difference monotonically. The midline of the right rib is on the right of the right "spiral" when $k=2.2$ and on the left of the right "spiral" when $k=2.4$, and the right rib is closer to the right "spiral" when $k=2.4$ than when $k=2.2$, which shows that the principal stress difference of the right rib is the lowest when $k=2.4$. Based on the above analysis, there are significant differences in roadway stability under different stress concentration coefficients. The stability of the roadway can be effectively improved by appropriately reducing the stress concentration coefficient of the roof and the two ribs such that they are near the center of the right "spiral." Within the scope of this study, when the stress concentration coefficient $k=2.2$, the principal stress difference of the midline of the two ribs and the roof is relatively small. In this case, the stability of the roadway is better.

4.3. Influence of the Coal Cohesion on Roadway Stability. Cohesion refers to the mutual attraction between neighboring molecules in the coal, which determines the strength properties of the coal and is an important parameter for calculating its shear strength. Based on the classic ideal elastoplastic theory and the Kastner formula, the radius of 

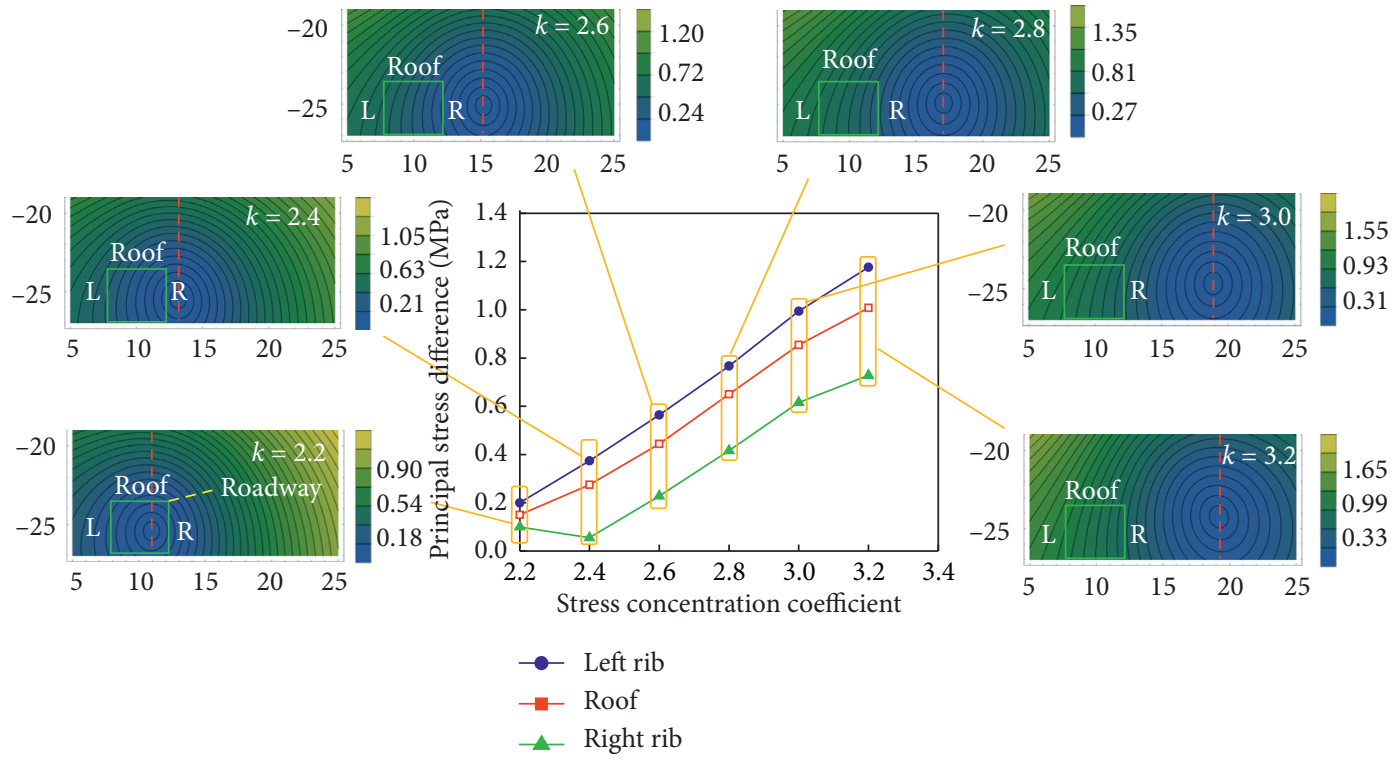

Figure 6: Principal stress differences under different stress concentration coefficients (unit: MPa).

the plastic zone and the deformation of the rock surrounding the roadway are closely related to the coal cohesion. To study the effect of coal cohesion on the stability of the roadway, $C=1.3,1.5,1.7,1.9,2.1$, and 2.3 MPa are selected. Based on Mathematica, the principal stress difference of the midline of the two ribs and the roof of the 13311 return airway is obtained, as shown in Figure 7.

Figure 7 shows that the principal stress difference of the two ribs and the roof of the roadway decreases with the increase in the coal cohesion, indicating that the roadway stability and coal cohesion are positively correlated, which is consistent with the calculation results of the Kastner formula. The principal stress difference of the left rib, roof, and right rib is reduced by $58 \%, 62 \%$, and $75 \%$, respectively, when the coal cohesion ranges from 1.3 to $2.3 \mathrm{MPa}$, which decreases approximately linearly. This is because increasing the coal cohesion can increase the strength and rigidity of the discontinuous surface inside the coal, thereby improving the bearing capacity of the coal. Therefore, increasing the coal cohesion will improve the shear resistance of the rock surrounding the roadway, thus strengthening the resistance to roadway deformation.

4.4. Influence of the Coal Internal Friction Angle on Roadway Stability. The internal friction angle of the coal depends on the surface friction between coal particles and the interlocking effect that characterizes the shear resistance of the coal and is a crucial factor in determining the bearing capacity of coal pillars. The Kastner formula demonstrates that the deformation of the rock surrounding the roadway is closely related to the internal friction angle of the coal. To study the effect of the internal friction angle on the stability of the roadway, $\varphi=24^{\circ}, 26^{\circ}, 28^{\circ}, 30^{\circ}, 32^{\circ}$, and $34^{\circ}$ are selected. Based on Mathematica, the principal stress difference of the midline of the two ribs and the roof of the 13311 return airway are obtained, as shown in Figure 8.

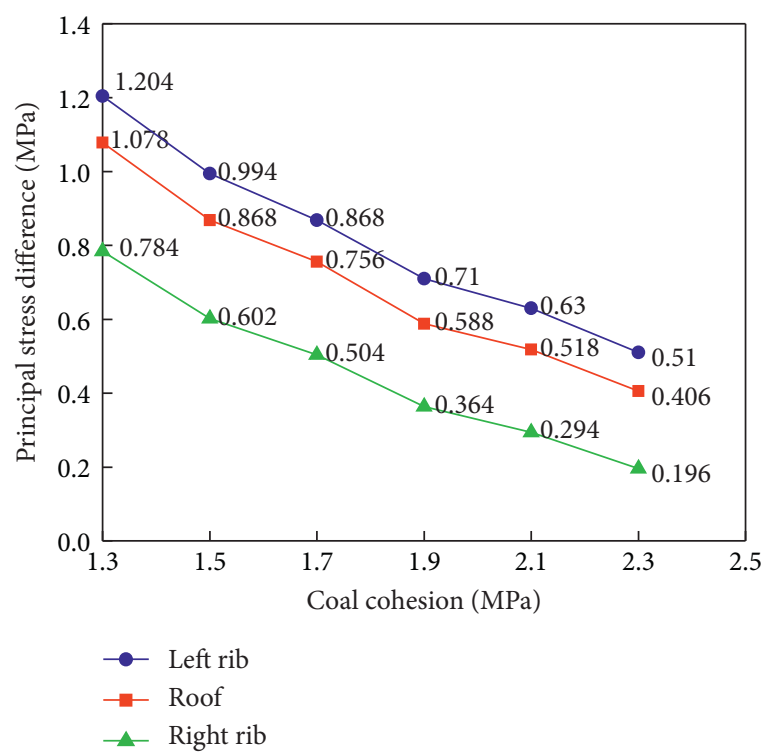

Figure 7: Principal stress difference at different coal cohesion strengths.

Figure 8 shows that the principal stress difference of the two ribs and the roof indicates a decreasing trend as the internal friction angle of the coal increases, confirming that the stability of the roadway and the internal friction angle of the coal are positively correlated. The principal stress difference of the left rib, roof, and right rib is reduced by approximately $16 \%, 20 \%$, and $25 \%$, respectively, when the internal friction angle of the coal ranges between $24^{\circ}$ and $26^{\circ}$. The rate of decrease is higher at this stage. However, the principal stress difference is reduced by approximately $13 \%$, $15 \%$, and $20 \%$ when the internal friction angle increases by $2^{\circ}$. The reason for a decrease in the principal stress difference with increasing internal friction angle is that, at the molecular level, the coal particles sliding over each other cause 


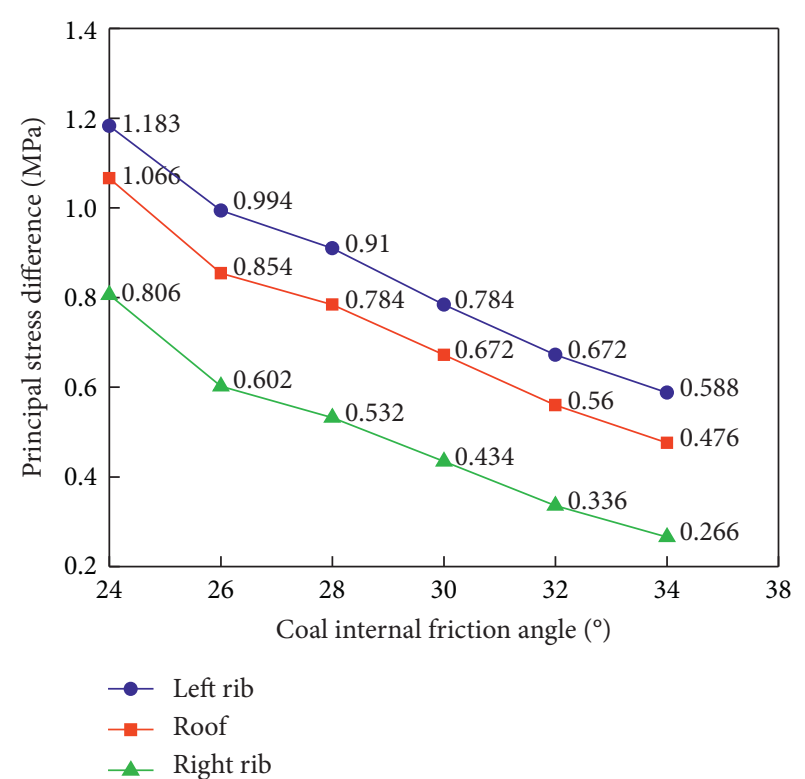

Figure 8: Principal stress differences at different coal internal friction angles.

instability, and the sliding is affected by the surface roughness and occlusal friction. The internal friction angle of coal is the critical self-stability angle needed to prevent the internal particles from shearing and sliding. Therefore, the larger the internal friction angle is, the better the self-stability of the coal structure. Therefore, increasing the internal friction angle can increase the strength of the rock surrounding the roadway, thereby enhancing the stability of the roadway.

4.5. Influence of the Working Face Length of the Upper Coal Seam on Roadway Stability. In the lower coal seam, after the working face is mined out, a supporting system of "coal walls-falling gangues" is formed. The supporting pressure along the inclined length of the working face is divided into a gradually compacted zone and the original rock stress zone. The primary factors affecting the extent of the gradually compacted zone are the mining height and rock-breaking expansion coefficient. However, for a specific coalmine roadway, the above factors are fixed, and the gradually compacted zone is certain even with different working face lengths. Therefore, how the length of the working face of the upper coal seam influences the stability of the roadway is reflected mainly in the width of the original rock stress zone, namely, the $\mathrm{AB}$ and IJ segments in Figure 2. To study how the length of the working face affects the stability of the roadway, $L=120,140,160,180,200$, and $220 \mathrm{~m}$ are selected. Based on Mathematica, the principal stress difference of the midline of the two ribs and the roof of the 13311 return airway is obtained, as shown in Figure 9.

Figure 9 shows that the principal stress difference of the two ribs and the roof indicates a decreasing trend with an increase in the length of the working face of the upper coal seam and confirms that the roadway stability and the working face length of the upper coal seam are positively

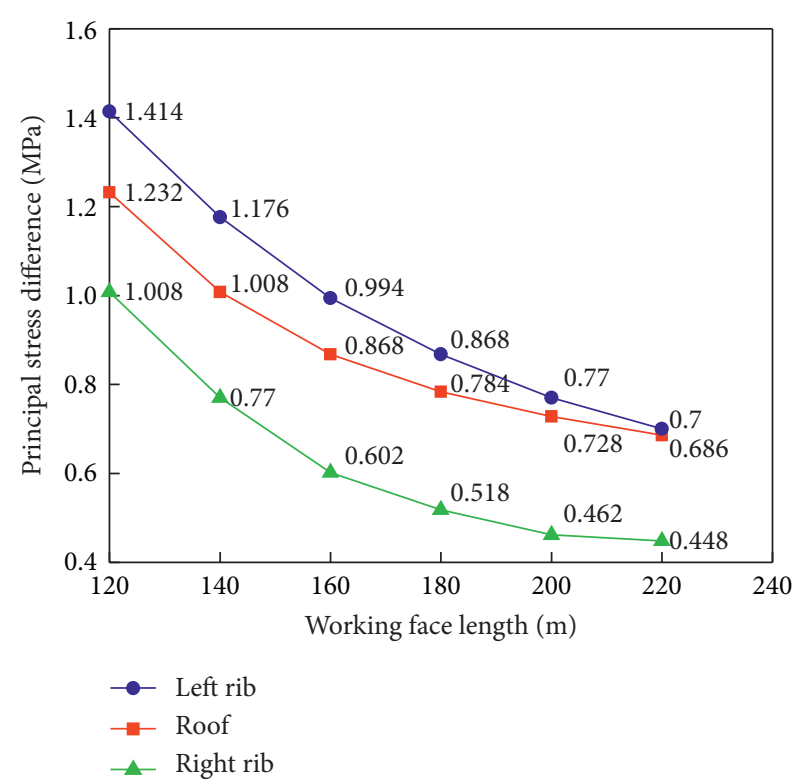

Figure 9: Principal stress difference under different working face lengths of the upper coal seam.

correlated. In Figure 9, the principal stress difference between the roof and the two ribs is approximately exponentially distributed. The principal stress difference in this research range first decreases rapidly and then gradually diminishes. The reason is that as the working face length of the upper coal seam increases, the widths of the AB and IJ segments of the original rock stress zone increase, while the supporting pressure in the upper coal pillar zone remains unchanged. Consequently, the roof and the two ribs of the roadway are gradually affected by the original rock stress zone on the right. When the working face of the upper coal seam is short, the rock surrounding the roadway is primarily subjected to the load of the coal pillar above, and the left rib is closer to the upper coal pillar; therefore, its principal stress difference is the largest. As the working face at the upper coal seam lengthens, the rock surrounding the roadway is gradually affected by the original rock stress zone above, and the stress of the surrounding rock tends to be even, thus reducing the principal stress difference. Simultaneously, the midline of the working face tends to be farther away from the 13311 return airway, and the influence of the lengthened working face on the stability of the roadway gradually weakens, thus demonstrating that the reduction rate of the principal stress difference gradually diminishes. As the working face length increases from $120 \mathrm{~m}$ to $220 \mathrm{~m}$, the principal stress difference between the left rib, roof, and right rib is reduced by approximately $50 \%, 44 \%$, and $56 \%$, respectively. Therefore, the stability of the roadway can be effectively improved by appropriately increasing the working face length of the upper coal seam.

\section{Verification by Field Testing}

5.1. Control Measures for Roadway Stability. The analysis of the 13311 return airway indicates that the stability of the lower coal seam roadway is significantly affected by the 
aforementioned five factors. Currently, the excavation of the 13311 working face is about to be completed. Therefore, this article will formulate the control measures for the next working face of the 13313 return airway based on the analysis of the 13311 return airway. However, the 13313 return airway has been excavated following an overlapping layout, rendering it impossible to lay the roadway in the center of the "spiral" where the principal stress difference is minimal. Based on the field conditions, the optimized factors influencing the stability of the roadway in Section 4 become an important means of ensuring the stability of the 13313 return airway. Because the roadway depth of the No. 13 coal seam is a fixed parameter and the No. 11 coal seam has been mined, the length of the working face of the upper coal seam cannot be changed. For the 13313 return airway, stability control measures can be formulated based on the stress concentration coefficient, coal cohesion, and coal internal friction angle.

5.1.1. Bolt (Cable) Support. The bolt (cable) has a specified shear resistance that can effectively improve the stress state of the surrounding rock, thereby improving the stability of the roadway [34]. Bolt (cable) support can increase the friction between the bedding surfaces by their squeezing action, limit the shear dislocation of the bedding surfaces, and indirectly increase the cohesion of the rock surrounding the roadway. As shown in Figure 10, a bolt (cable) support scheme for the 13313 return airway is designed for this study. The roof support adopts three $5200 \mathrm{~mm}$ short cables and two $8200 \mathrm{~mm}$ long cables with $\Phi 21.8 \mathrm{~mm}$ and $1 \times 19$ steel strands, with a row spacing of $1000 \mathrm{~mm} \times 1000 \mathrm{~mm}$ and an initial preload stress of not less than $300 \mathrm{kN}$. The two rib supports adopt four HRB500 highstrength left-handed threaded steel bolts without longitudinal reinforcement of $\Phi 20 \mathrm{~mm}$, with a row spacing of $900 \mathrm{~mm} \times 1000 \mathrm{~mm}$ and a pretightening torque of $400 \mathrm{Nm}$.

5.1.2. Pressure Relief Drilling. According to the above analysis, the stability of the lower coal seam roadway increases as the stress concentration coefficient decreases. Through pressure relief drilling, the rock surrounding the roadway can be unloaded to a certain extent, and the concentrated load originally acting on the roadway is transferred distantly, reducing the stress concentration coefficient in the stress increase zone and achieving the purpose of improving the roadway stability.

5.1.3. Pregrouting. According to the above analysis, the stability of the lower coal seam roadway will increase with an increase in coal cohesion and the internal friction angle. Pregrouting can increase coal cohesion and the internal friction angle and improve the shear strength and deformation rigidity of the fracture surface, thus improving the surrounding rock deformation caused by mining and the stability of the roadway. By adopting pregrouting in some areas of the 13313 return airway, the surrounding rock deformation in this area is small, which verifies the effectiveness of the measure.

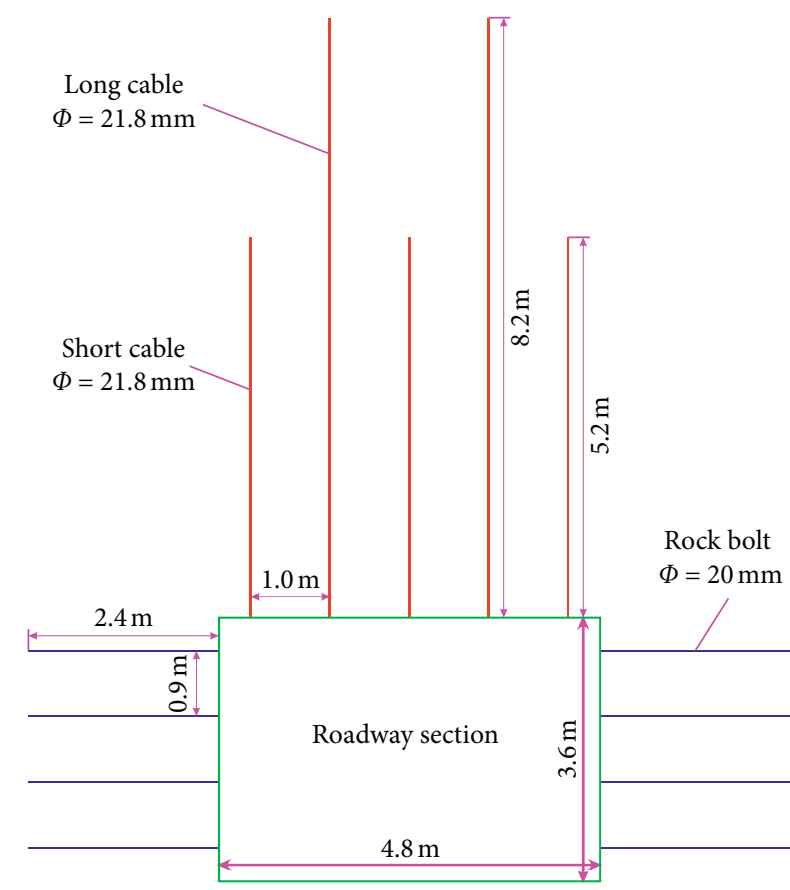

FIgURE 10: Support scheme for the 13313 return airway.

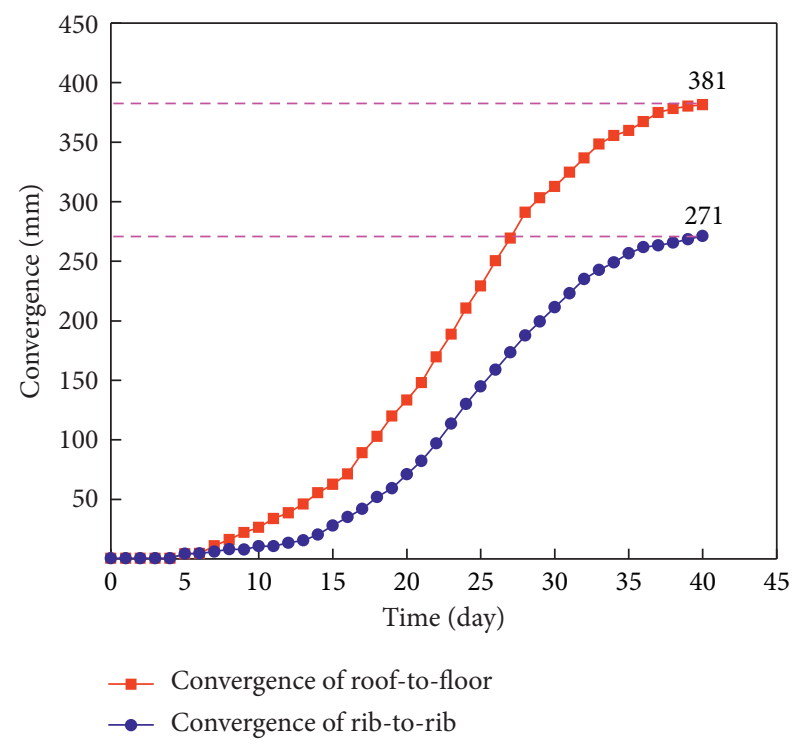

FIGURE 11: Deformation of the rock surrounding the roadway.

5.2. Field Deformation Measurements of the Rock Surrounding the Roadway. To verify the effectiveness of the above measures, the surface displacement of the 13313 return airway was monitored in the field. The monitoring results are shown in Figure 11.

Field tests show that measures such as bolt (cable) support, pressure relief drilling, and pregrouting significantly reduce the roof-to-floor and rib-to-rib convergence of the 13313 return airway. The maximum roof-to-floor deformation is $381 \mathrm{~mm}$, and the maximum rib-to-rib deformation is $271 \mathrm{~mm}$. Compared with the deformation of the 13311 return airway, which is generally more than $2000 \mathrm{~mm}$, 
the deformation of the surrounding rock after the aforementioned measures is reduced by more than $80 \%$, thereby effectively improving the stability of the roadway.

\section{Conclusions}

(1) The principal stress difference of the 13311 return airway regards the centerline of the upper coal pillar as the axis of symmetry and is transmitted radially downward through the floor. The principal stress difference of the rock surrounding the roadway gradually decreases with the distance from the upper coal pillar and can be ranked in the following order: left rib $>$ roof $>$ right rib, which is consistent with the deformation observed in the field:

(2) The minimum values of the principal stress differences are located at the centers of the left and right "spirals" obliquely below the edges of both sides of the upper coal pillar, which is an ideal position for the lower coal seam roadway.

(3) According to the rock mass limit equilibrium theory and the mechanical model of close-distance coal seams and the roadway stability criterion $\sigma_{s}$, it is demonstrated that the shallowness of the roadway, small stress concentration coefficient, high coal cohesion, large coal internal friction angle, and appropriate lengthening of the working face at the upper coal seam are conducive to improving the stability of the rock surrounding the lower coal seam roadway.

\section{Data Availability}

The data supporting the conclusion of the article are shown in the relevant figures and tables in the article.

\section{Conflicts of Interest}

The authors declare no conflicts of interest.

\section{Authors' Contributions}

All of the authors contributed extensively to the work. Zhuoyue Sun and Zhiguo Lu contributed to theoretical analysis. Xiaowei Chu, Youliang FENG, and Kang Yi analyzed the data. Zhuoyue Sun wrote the paper. Yongzheng $\mathrm{Wu}$ modified the manuscript.

\section{Acknowledgments}

This work was supported by the Youth Fund of Mining \& Designing Branch of Tiandi Technology Co., Ltd. (Grant no. 2019-TD-QN003) and the National Natural Science Foundation of China (Grant no. 51774186).

\section{References}

[1] H. P. Kang, J. Lin, and M. J. Fan, "Investigation on support pattern of a coal mine roadway within soft rocks-a case study,"
International Journal of Coal Geology, vol. 140, pp. 31-40, 2015.

[2] N. M. Michieka, "Energy and the environment: the relationship between coal production and the environment in China," Natural Resources Research, vol. 23, no. 2, pp. 285-298, 2014.

[3] R. Kumar, A. K. Singh, A. K. Mishra, and R. Singh, "Underground mining of thick coal seams," International Journal of Mining Science and Technology, vol. 25, no. 6, pp. 885-896, 2015.

[4] G. C. Zhang, Z. J. Wen, S. J. Liang et al., "Ground response of a gob-side entry in a longwall panel extracting $17 \mathrm{~m}$-thick coal seam: a case study," Rock Mechanics and Rock Engineering, vol. 53, no. 2, pp. 497-516, 2020.

[5] X. Sun, Y. Liu, J. Wang, J. Li, S. Sun, and X. Cui, "Study on three-dimensional stress field of gob-side entry retaining by roof cutting without pillar under near-group coal seam mining," Processes, vol. 7, no. 9, p. 552, 2019.

[6] T.-B. Zhao, W.-Y. Guo, Y.-L. Tan, Y.-C. Yin, L.-S. Cai, and J.-F. Pan, "Case studies of rock bursts under complicated geological conditions during multi-seam mining at a depth of 800 m," Rock Mechanics and Rock Engineering, vol. 51, no. 5, pp. 1539-1564, 2018.

[7] Y. L. Tan, T. B. Zhao, and Y. X. Xiao, "In situ investigations of failure zone of floor strata in mining close distance coal seams," International Journal of Rock Mechanics and Mining Sciences, vol. 47, no. 5, pp. 865-870, 2010.

[8] J. Ning, J. Wang, Y. Tan, and Q. Xu, "Mechanical mechanism of overlying strata breaking and development of fractured zone during close-distance coal seam group mining," International Journal of Mining Science and Technology, vol. 30, no. 2, pp. 207-215, 2020.

[9] M. R. Islam and R. Shinjo, "Numerical simulation of stress distributions and displacements around an entry roadway with igneous intrusion and potential sources of seam gas emission of the Barapukuria coal mine, NW Bangladesh," International Journal of Coal Geology, vol. 78, no. 4, pp. 249-262, 2009.

[10] G.-C. Zhang, F.-L. He, H.-G. Jia, and Y.-H. Lai, "Analysis of gateroad stability in relation to yield pillar size: a case study," Rock Mechanics and Rock Engineering, vol. 50, no. 5, pp. 1263-1278, 2017.

[11] M. Zhang, H. Shimada, T. Sasaoka, K. Matsui, and L. Dou, "Evolution and effect of the stress concentration and rock failure in the deep multi-seam coal mining," Environmental Earth Sciences, vol. 72, no. 3, pp. 629-643, 2014.

[12] C. Zhang, R. Feng, X. Zhang, and W. Shen, "Numerical study on stress relief and fracture distribution law of floor in short-distance coal seams mining: a case study," Geotechnical and Geological Engineering, vol. 38, no. 2, pp. 1-14, 2020.

[13] W. Yang, B.-Q. Lin, Y.-A. Qu et al., "Stress evolution with time and space during mining of a coal seam," International Journal of Rock Mechanics and Mining Sciences, vol. 48, no. 7, pp. 1145-1152, 2011.

[14] Z. Zhang, M. Deng, X. Wang, W. Yu, F. Zhang, and V. D. Dao, "Field and numerical investigations on the lower coal seam entry failure analysis under the remnant pillar," Engineering Failure Analysis, vol. 115, p. 104638, 2020.

[15] P. Wang, J. Zhao, G. Feng, and Z. Wang, "Interaction between vertical stress distribution within the goaf and surrounding rock mass in longwall panel systems," Journal of the Southern African Institute of Mining and Metallurgy, vol. 118, no. 7, p. 745, 2018. 
[16] G. Wu, X. Fang, H. Bai, and M. Liang, "Optimization of roadway layout in ultra-close coal seams: a case study," Plos One, vol. 13, no. 11, Article ID e0207447, 2018.

[17] G. S. P. Singh and U. K. Singh, "Assessment of goaf characteristics and compaction in longwall caving," Mining Technology, vol. 120, no. 4, pp. 222-232, 2011.

[18] Y. Xu, K. Pan, and H. Zhang, "Investigation of key techniques on floor roadway support under the impacts of superimposed mining: theoretical analysis and field study," Environmental Earth Science, vol. 78, no. 15, pp. 436-450, 2019.

[19] A. M. Iwanec, J. P. Carter, and J. P. Hambleton, "Geomechanics of subsidence above single and multi-seam coal mining," Journal of Rock Mechanics and Geotechnical Engineering, vol. 8, no. 3, pp. 304-313, 2016.

[20] W. Zhang, D. Zhang, D. Qi, W. Hu, Z. He, and W. Zhang, "Floor failure depth of upper coal seam during close coal seams mining and its novel detection method," Energy Exploration \& Exploitation, vol. 36, no. 5, pp. 1265-1278, 2018.

[21] X. Liu, X. Li, and W. Pan, "Analysis on the floor stress distribution and roadway position in the close distance coal seams," Arabian Journal of Geosciences, vol. 9, no. 2, p. 83, 2016.

[22] B. Zhang, S. Yang, L. Kang, and Y. Zhai, "Discussion on method for determining reasonable position of roadway for ultra-close multi-seam," Chinese Journal of Rock Mechanics and Engineering, vol. 27, no. 1, pp. 97-101, 2008.

[23] X. Fang, M. Guo, and Z. Lv, "Instability mechanism and prevention of roadway under close-distance seam group mining," Chinese Journal of Rock Mechanics and Engineering, vol. 28, no. 10, pp. 2059-2067, 2009.

[24] J. Zuo, J. Wang, and Y. Jiang, "Macro/meso failure behavior of surrounding rock in deep roadway and its control technology," International Journal of Coal Science \& Technology, vol. 6, no. 3, pp. 301-319, 2019.

[25] Z. Xie, N. Zhang, X. Feng, D. Liang, Q. Wei, and M. Weng, "Investigation on the evolution and control of surrounding rock fracture under different supporting conditions in deep roadway during excavation period," International Journal of Rock Mechanics and Mining Sciences, vol. 123, Article ID 104122, 2019.

[26] B. Shen, "Coal mine roadway stability in soft rock: a case study," Rock Mechanics and Rock Engineering, vol. 47, no. 6, pp. 2225-2238, 2014.

[27] S. C. Li, Q. Wang, H. T. Wang et al., "Model test study on surrounding rock deformation and failure mechanisms of deep roadways with thick top coal," Tunnelling and Underground Space Technology, vol. 47, pp. 52-63, 2015.

[28] Y. Yu, X. Wang, J. Bai, L. Zhang, and H. Xia, "Deformation mechanism and stability control of roadway surrounding rock with compound roof: research and applications," Energies, vol. 13, no. 6, p. 1350, 2020.

[29] C. Hou and N. Ma, "Stress in in-seam roadway sides and limit equilibrium zone," Journal of China Coal Society, vol. 14, no. 4, pp. 21-29, 1989.

[30] D. Y. Hao, Y. Z. Wu, H. J. Chen, X. Q. Chu, and Y. Li, "Instability mechanism and prevention technology of roadway in close distance and extra thick coal seam under goaf," Journal of China Coal Society, vol. 44, no. 9, pp. 2682-2690, 2019.

[31] J. Zhang, Y. Zhang, and T. Liu, Rock Mass Seepage and Water Inrush from Coal Seam Floor, pp. 6-8, Geological Publishing House, Beijing, China, 1997.

[32] Z. Xu, A Concise Course in Elasticity, pp. 84-86, Higher education press, Beijing, China, 2006.
[33] Z. Lu, W. Ju, Y. Zhao, H. Wang, J. Zheng, and A. Liu, "Analysis of the mining induced stress rotation influence on fault stability," Rock and Soil Mechanics, vol. 40, no. 11, pp. 4459-4466, 2019.

[34] Y. Wu, F. Gao, J. Chen, and J. He, "Experimental study on the performance of rock bolts in coal burst-prone mines," Rock Mechanics and Rock Engineering, vol. 52, no. 10, pp. 39593970, 2019. 